\title{
Strategies for Preventing and Responding to Sexual Violence against Children in Rombo District, Tanzania: A Mixed Method Study
}

\author{
Michael Reuben ${ }^{1}$, Fauzia Mohamed1, Felician Mutasa² \\ ${ }^{1}$ Department of Sociology and Social Work, The Open University of Tanzania, Dar es Salaam, Tanzania \\ ${ }^{2}$ Center for Economics and Community Economic Development, The Open University of Tanzania, Dar es Salaam, Tanzania \\ Email: ^michaelreuben15@gmail.com, fauhamed@gmail.com, felicianmutasa@yahoo.com
}

How to cite this paper: Reuben, M., Mohamed, F., \& Mutasa, F. (2021). Strategies for Preventing and Responding to Sexual Violence against Children in Rombo District, Tanzania: A Mixed Method Study. Open Journal of Social Sciences, 9, 439-453. https://doi.org/10.4236/jss.2021.99032

Received: August 6, 2021

Accepted: September 15, 2021

Published: September 18, 2021

Copyright $\odot 2021$ by author(s) and Scientific Research Publishing Inc. This work is licensed under the Creative Commons Attribution International License (CC BY 4.0).

http://creativecommons.org/licenses/by/4.0/

\begin{abstract}
This paper examined the strategies for preventing and responding to sexual violence against children in Rombo district, Tanzania. Sexual violence against children (SVAC) remains a major concern in many countries across the globe and in developing countries such as Tanzania. The SVAC encompasses a range of offenses such as completed non-consensual sex acts such as rape, attempted non-consensual sex acts, abusive sexual contacts such as unwanted sexual touching and non-contact sexual abuse. Studies have been conducted to assess strategies to prevent and respond to sexual violence against children. However, studies that focus on examining the strategies and how they are used by Community Based Child Protection Mechanisms (CBCPMs) are still limited in Tanzania. Therefore, this study aimed to examine the strategies used by CBCPMs to prevent and respond to sexual violence against children in Rombo District, Tanzania. A mixed methods study was conducted involving 158 members of CBCPMs. A total of 108 responded to a questionnaire, 4 Focus Group Discussions (FGDs) were conducted involving 40 members of CBCPMs and 10 Key Informant Interviews (KIIs) were conducted to complement data collected through questionnaire. Descriptive data analysis was conducted with the aid of Statistical Package for Social Scientists (SPSS) version 23. Qualitative data was analyzed using thematic content analysis. The study concludes that awareness raising, provision of advice, communication, identification of children, referral of abused children, mapping and monitoring of children had effects on combating SVAC. The study revealed that CBCPMs have improved situation of SVAC and child protection environment in Rombo district. Therefore, study recommends that, the government should support CBCPMs through funding, monitoring and capacity building in order to strengthen their skills to combat SVAC. The study also recommends that more awareness raising
\end{abstract}


should be carried out to the community in order to address sexual violence against children.

\section{Keywords}

Sexual Violence, Children, Community-Based Mechanisms, Rombo, Tanzania

\section{Introduction}

Sexual violence against children (SVAC) remains a major concern in many countries in the globe particularly developing countries such as Tanzania (Ligiero et al., 2019). SVAC encompasses a range of offenses such as completed non-consensual sex acts such as rape, attempted non-consensual sex acts, abusive sexual contacts (i.e. unwanted sexual touching) and non-contact sexual abuse (e.g. threatened sexual violence, verbal (UNICEF et al., 2011). This study was conducted in Tanzania to examine the strategies used by Community Based Child Protection Mechanisms(CBCPMs). Tanzania was selected because it is one of the pathfinder countries and the first African country to showcase the initiative to End Violence against Women and children (NPA-VAWC 2017/2018-2021/2022).

In Brazil the past studies show that sexual violence against children was related to school structure and lack of discussion on the subject matter (Pereira et al., 2020). Similarly, in Indonesia, the study found that the root causes of sexual violence against children were family disharmony, religious values, uncomfortable environment, technology and internet and lack of education (Rosyadi, 2016).

In Tanzania, National Violence against Children (VAC) survey found nearly 3 out of every 10 females aged 13 to 24 in Tanzania reported experiencing at least one incidence of sexual violence before turning 18. Among men in the same age group, 13.4\% reported experiencing at least one incident of sexual violence before the age of 18 (UNICEF et al., 2011). The literature also provides that child rape incidents increased in the first six months from 759 incidents in January 2018 to 2365 in June 2018 due to poor parenting, lack of parenthood and childcare, knowledge among parents, household poverty leaving children especially girls vulnerable to men who give them money for food, and conflict among parents (LHRC, 2018).

Similarly, LHRC (2020) found sexual violence against children as the biggest threat to children's rights. Trends in the past five years indicate that incidents of rape and sodomy have been on the rise. For the period of 2015 to 2019 a total of 26,940 rape incidents including children recorded by the Police were equal to 7388 per annum. Ezekiel et al. (2017) found that globalization was one of the factors that contribute to sexual violence. Further studies in Kilombero, Morogoro found effects of alcohol/illicit drugs, effects of pornographic film, culture and community-poor knowledge toward rape and child sexual abuse (Abeid et al., 2015: p. 1).

Sexual violence against children is a complex problem driven by many factors at 
the level of individuals, relationship, family, community and the broader society. This review is similar to the current study in terms of causes. It is supported by Social Ecological Theory by Bronfenbrenner (1998) which stipulates the importance to understand agencies that treat and prevent abuse and sexual violence against children and how they are linked to settings such as home and schools.

Due to the trend and prevailing of SVAC, Tanzania has taken efforts to combat SVAC, example, under the National Plan of Action to End Violence against Women and Children (NPA VAWC 2017/2018-2021/2022), the government of Tanzania has established community based child protection mechanisms/committees to prevent and respond to SVAC across the country. The Child Protection Committees (CPCs) have been using different strategies such as awarenessraising, provision of advice, mapping of service providers and door-to-door campaigns and the same initiatives was adapted by child protection committees Uganda, Kenya, the Democratic Republic of Congo, and Ethiopia (War Child, 2010; Plan International, 2017).

Despite the efforts, there is still a gap in Tanzania in understanding which strategies are used by Community Based Child Protection Mechanisms to prevent and respond to sexual violence against children. Therefore, this study aimed to fill this gap by examining the strategies which are commonly used by CBCPMs and how they are used in preventing and responding to sexual violence against children.

\section{Methods}

The study was conducted in Rombo District in Kilimanjaro region located in the northern part of Tanzania. Tanzania is part of the East African country with a population of 57.6 million and a growth rate of 3.1 percent (URT, 2020). The study area was selected because of the prevalence of child sexual violence in the area (LHRC, 2018). This study used a mixed methods approach.

The questionnaire was developed with open and closed ended questions with the questions about the strategies to prevent and respond to sexual violence against children. Two research assistants were recruited and trained on child protection, objective of the study, study ethics, data collection and data entry. FGD and interview guides were developed to collect qualitative data on strategies.

Pilot study to test the questionnaire was done and revision to incorporate changes and modifications was done. The respondents of the study were members of women and child protection mechanism/committees from 10 wards of Rombo district. Only wards with women and child protection committees were purposely selected. Individual respondents were selected using simple random sampling and purposive sampling. Prior to data collection, research assistants were provided with contact details of respondents, which they used to reach individuals to agree the location to meet for administering questionnaires. Data was collected from December 2018 to March 2019.

The study participants were required to respond "Yes" or "No" on the follow- 
ing statements preceded by the question which asked; Which of the following is among the strategies which you use to prevent SVAC and which of the following is among the strategies to respond to SVAC; 1) Awareness raising 2) Provision of advice 3) Speedy access to child protection services for victims 4) mapping of service providers 5) monitoring of children rights. These questions were developed after a thorough literature review. Questionnaire was used in order to provide standardized results that are tabulated and treated statistically (Rwegoshora, 2014).

A total of 108 (40.1\% male and 51.9 female) respondents who took part in a study were randomly selected using rotary method and 40 FGDs participants and 10 Key Informant interview participants were purposively sampled. Guest at el. (2017) suggest that $90 \%$ of themes are discoverable within 3 to 6 FGDs. The sample size for this study was guided by Yamane (1967) formula for sample calculation $n=\frac{N}{1+N(e)^{2}}$. Where $\mathrm{n}$ is the sample size, $N$ is the population size, confidence level of $95 \%$ and e as level of precision $= \pm 5 \%$ (Sarmah \& Hazarika, 2012). The population of this study was 258 . The FGDs and interviews were conducted in Kiswahili because the study participants know to speak Kiswahili as a National language for Tanzania.

The study adapted mixed method approach in order to triangulate data. The study used concurrent design in order to get in-depth understanding of the subject matter. The approach enabled the researchers to collect data simultaneously. However, data set were analyzed separately and merged. Quantitative data were analyzed with the aid of Statistical Package for Social Scientists (SPSS) version 23 to produce descriptive results through frequency and percentage. Qualitative data were analyzed through content analysis. The study obtained research clearance from the Open University of Tanzania, Rombo District Council and at ward levels.

The study also received informed consent and used the principle of do no harm, respect for anonymity focus on caring, preventing harm. Data were kept anonymous to protect study participants; no names of participants were taken.

\section{Findings}

\subsection{The Characteristic of Respondents}

The respondents had different characteristics. The percentage of females were higher than that of males and majority (47.2\%) of the respondents fell in the age category of 36 - 52 years because according to the NPA VAWC guidelines majority of the committee members are adult from government departments, parents and representatives of different marginalized groups and few children. At the time of interview some of children had already finished their primary and secondary school education and could not be traced because they did not have mobile numbers. The median age was 46.50 (12 - 70) years. Majority (47.2\%) had primary education and $(38 \%)$ of the respondents were farmers. The distribution of respondents by age, gender, education and occupation was to get a diverse view of people across different locations in the study area (Table 1). 
Table 1. Characteristics of respondents $(n=108)$.

\begin{tabular}{ccc}
\hline Demographics characteristics & Frequency & Percent \\
\hline Sex & 52 & 48.1 \\
Male & 56 & 51.9 \\
Female & & \\
Age category (Years) & 6 & 5.6 \\
$12-18$ & 22 & 20.4 \\
$19-35$ & 51 & 47.2 \\
$36-52$ & 29 & 26.9 \\
$>52$ & $46.50(12-70)$ & \\
Median (Min-Max) & & 36.2 \\
Level of education & 39 & 16.7 \\
College/university & 18 & 47.2 \\
Secondary & 51 & 32.4 \\
Primary Education & & 18.5 \\
Occupation & 35 & 38.0 \\
Farmer & 41 & 11.1 \\
Business & & \\
Government employee & & \\
Others & & \\
\hline
\end{tabular}

Source: Field data, 2018/2019.

\subsection{Strategies for Preventing and Responding to Sexual Violence against Children in the Study Area}

\subsubsection{Awareness Raising toward SVAC}

Awareness raising to combat sexual violence was analyzed using multiple responses and results reveal that (96.2\%) of child protection committee respondents ranked it as the most commonly used strategy to combat sexual violence against children. The respondents from FGDs revealed that it is one of the strategies which was commonly used by protection committee in the study area on the campaigns to end SVAC.

\section{One participant claimed that;}

"We have ensured that prevention of sexual violence against children to be a permanent agenda in village and ward meetings. Apart from our collective responsibilities, we have agreed that individuals to provide education at his/her own time (FGD, Male, Rombo)."

The quote indicates that various initiatives are taken by the village government to combat sexual violence against children by the means of educating people.

\subsubsection{Provision of Advice toward Combating SVAC}

Advice was frequently mentioned by child protection committees' respondents as a strategy which was also used. In responding to the statement which says "we 
use advice on ending child sexual violence," the multiple response analysis found that $(82.1 \%)$ of respondents supported that the protection committees have been providing advice on sexual violence against children.

\subsubsection{Communication as a Tool toward SVAC}

The multiple responses, indicated that $(82.1 \%)$ of respondents mentioned communication as among the strategy to combat sexual violence. Participants were responding to the question which asked that "we promote communication with other child protection actors to combat sexual violence against children". The participants in the FGDs and interviews had the view that to strengthen collaboration, CBCPMs have been communicating with Police, NGOs such KWIECO was one of the NGO in Kilimanjaro which collaborated with government to establish CBCPMs in particular, women and child protection committees. and AJISO, children, teachers and parents as an effort to combat SVAC.

One key informant asserted that;

"There is no way we can address sexual violence if the collaboration and communication channels are not functional. Communication is a strategy which we need to strengthen in order to address sexual violence (In-depth Interview, Female, Rombo)."

This quote indicates that communication is key to addressing sexual violence against children. The CBCPMs has a great role to play in communication.

\subsubsection{Identification of Children as a Strategy to Combat SVAC}

The results showed that child protection committees have been using child identification to support the protection of children or response on sexual violence. Of all 108 respondents, as indicated (69.8\%) agreed that they have been using child identification in combating sexual violence. for example through school clubs, counseling teachers, parents and community members, they provide secret information to keep themselves safe from the perpetrators. The participants further extended that children were identified by observing the home environment they live.

"One of our strategy is to ensure that we identify children at risks of sexual violence, talk to children themselves in schools during our interventions. We engage parents to give us information when they find or hear of children at risks and we have also been using members of religious institutions to identify children as well (Male, FGD, Rombo)."

The quotes indicate how the committee uses different ways to combat sexual violence against children such as identification of children in collaboration with other child protection actors.

\subsubsection{Referral to Handle Sexual Violence against Children}

The study examined child referral and found that a total of (74.5\%) as presented in (Table 2) agreed that protection committees conduct referral of cases of sexual violence to relevant authorities such as Police, health and Social Welfare departments. They were responding to the question, which asked, "child referral is one of the strategies used to combat sexual violence against children". As taken 
Table 2. Multiple responses on strategies for preventing and responding to SVAC.

\begin{tabular}{lcc}
\hline \multicolumn{1}{c}{ Strategies } & n & $\begin{array}{c}\text { \% of } \\
\text { cases }\end{array}$ \\
\hline Awareness raising towards sexual violence against children & 102 & 96.2 \\
$\begin{array}{l}\text { Communication as a tool towards sexual violence against children } \\
\begin{array}{l}\text { Identification of at risk children as a strategy to combat sexual violence } \\
\text { against children }\end{array}\end{array}$ & 87 & 82.1 \\
$\begin{array}{l}\text { Speedy access to services on sexual violence against children } \\
\begin{array}{l}\text { Mapping of service providers in order to protect sexual violence against children } \\
\text { Monitoring of children rights so as to overcome sexual violence against children }\end{array}\end{array}$ & 73 & 69.8 \\
Door to door campaign towards sexual combating violence against children & 14 & 69.9 \\
\hline
\end{tabular}

Source: (Field data, 2018/2019).

from FGD, CBCPMs refer cases to Police Gender and Children desk to get PF3, then hospital for check up and alter on the case is taken to the court for hearing.

\subsubsection{Speedy Access to Child Protection Services on SVAC}

The establishments of the CBCPMs have improved speedy access to child protection services. The respondents to the tune of (62.3\%) supported the contention that the child protection committees have improved speedy access to child protection services. As from FGD's participants the findings tell us that CBCPMs have improved speedy access because committee members have been identified from different groups at village, ward and district level.

\subsubsection{Mapping of Service Providers on SVAC}

A total of (68.9\%) respondents agreed that protection committees use mapping to identify other service providers available in the community to work together in providing services, such as NGOs and informal groups. The majority supported mapping of service providers has been one of the usable strategies to end child sexual violence (Table 2). The response from FGD and interview sessions regarding mapping of service providers indicated that the CВCPMs have mapped other service providers to work together to respond and prevent sexual violence against children.

"Preventing children from sexual violence is not the responsibility of the child protection committee alone, it is a concerted efforts where different individuals, groups, NGOs have to be part of the intervention (Male, FGD, Rombo)."

\subsubsection{Monitoring Child Rights to Overcome SVAC}

In responding to the question, which asked whether monitoring of child rights have been used as a strategy. The study indicates (69.8\%) agreed that these child protection committees have been using monitoring to protect children from sexual violence (Table 2). This finding was generated through multiple responses, where most protection committee respondents agreed that they have been using it to end sexual violence against children. The findings from FGD illustrate that 
monitoring is done by CBCPMs in groups or individually depending on the situation to some families in the community. They have been monitoring children in schools and in the communities.

\subsubsection{Door to Door Campaigns}

Door to door campaigns was less commonly used in the study area. The study revealed that (13.2\%) of respondents agreed that door to door was uncommonly used by the protection committees on addressing sexual violence (Table 2). The FGD and interview participants cited that this strategy was less useful because of some limitations on the side of CBCPMs such as inadequate time of committee members, costs involved and economic activities of parents, which could make it difficult to find parents at home. Most communities are busy with farm and enentrepreneurship activities, therefore you cannot find them at home. One respondent said that

"We cannot manage door to door because we have a limited time, for example I run a small shop and sell local brew, I have to be around all the time in the morning to evening to save my customers (FGD participant, Rombo)."

The quote indicates that door to door did not work well in the context of Rombo due to some challenges associated with its use.

\section{Discussion of Findings}

\subsection{Awareness Raising Regarding Sexual Violence against Children}

The most reported findings was awareness raising which indicated that awareness raising have been used to prevent sexual violence against children in the study area. The findings concur with the findings of studies conducted in Thailand, Zimbabwe, and Ethiopia where religious leaders have incorporate child rights in their teaching (Muzingili \& Mushayamunda, 2015; Plan International, 2017). Information from key informants indicates that, associations such as VICOBA (Village Community Banks), groups of men and women entrepreneurs are a good entry point and an avenue of engaging people in the efforts of addressing sexual violence against children in Rombo district.

These CPCs conduct awareness raising among different group of community members such as women, men, youth, girls and boys on child rights, protection issues, and education on parenting. The awareness raising has led to increased awareness, galvanized community efforts to prevent SVAC and parents becoming vigilant to be agent of change on SVAC.

Children in the protection committees in Rombo District use clubs, while in Sri Lanka, children raised awareness through drama, theatre for development, music, art and child led media initiatives such as newsletters, magazine, radio and TV program (ICPREC, 2012). The findings of this study are in contrast with the findings in a study by Wessells (2011) who revealed that in some chiefdom in Sierra Leone such as Bombali and Mnyamba districts, government designated Social Workers raised awareness on children's issues in prevention and response 
to child abuse. In this study, there was a shortage of Social workers in carrying out such a responsibility. Despite the efforts, CBCPMs had challenges of funding to meet costs of transport to reach many people and inadequate skills on sexual violence and prevention.

\subsection{Provision of Advice in Addressing Sexual Violence against Children}

In this study, the provision of advice was associated with addressing sexual violence against children. The study participants pointed out that teachers in collaboration with other members of the protection committees advise parents to fulfil their role and responsibilities on caring for children as stipulated in section 8 (1) of the Law of child Act in Tanzania (URT, 2009). The key informant said that, as a result of advice provided, some parents have started to fulfil their responsibilities by providing basic needs, care and protection of their children against abuse. This view concurs with the view in a study by Wessells et al. (2014) who suggests that in Kilifi, Mombasa, for example, child protection committees worked with parents and addressed family members who in turn provided advice to their children, taught their children good values, behaviour, and how to avoid sexual violence.

This finding is also similar to the finding in a study by Muzingili and Mushayamunda (2015) who found that a similar strategy was used by child protection committees in Zimbabwe. The study revealed that, the Child Protection Protocol of 2012 substantiate that Child Protection Committees (CPCs) may use advice on how the community can help in the protection of children and have strategies in place to do so..

\subsection{Communication as a Tool towards Sexual Violence against Children}

The findings of the present study show that communication is a tool which have been used to address sexual violence against children. The study emphasizes on the use of communication among child protection actors in the efforts of combating sexual violence against children. Obi-Keguna et al. (2017) in Nigeria revealed further that Social Workers communicate with clients as well as other professionals on matters relevant to client's needs. Communication is central and without it, humans cannot co-exist (Obi-Keguna et al., 2017). The theoretical contribution of this study is that it has confirmed that Social Network Theory impacts understanding the importance of communication between CBCPMs towards their common goal. The CBCPMs have made a good progress in terms of communicating among themselves and with other actors on ways to handle SVAC together though some CBCPMs felt left out of communication especially those who are not government employees. Some of the CBCPMs members claimed that since they are not meeting with government employees regularly and they are not formally employed by the government, they felt to have been left out of the communications. 


\subsection{Identification of Children as Strategy for Addressing Sexual Violence against Children}

Identification of children is an important predicator of sexual violence against children and can contributes to address sexual violence against children. These results is similar to NPA-VAWC which indicates that, child protection committees should also be responsible for identifying high-risk areas and children and develop strategies or plan of reducing (NPA VAWC 2017/2018 2021/2022). However, at the time when the study was conducted in Rombo, some committee members reported to have not started identification of children at risk against sexual violence due to lack of plans and skills to identify children at risk of SVAC.

However, these perception are not in agreement with Radford et al. (2015) who found that identifying sexually abused and exploited children is a difficult task due to barriers of children' disclosure of these abuses. On the other hand, Gwanyemba et al. (2016) argue that parents, caregivers, and children were able to report incidence of abuse because they were educated on where to report once a child was faced with sexual violence or other harmful practices. The reasons for these varying arguments could be attributed to increased awareness and readiness of parents, caregivers, and children to report cases of child sexual abuse.

\subsection{Referral to Handle Sexual Violence against Children}

Referral had contributed to the efforts of addressing sexual violence against children. The present study revealed that, protection committees in Rombo District conducted referrals to relevant departments such as the Police Gender and Children Desk and Social Welfare. However, the committee members mentioned that they were dissatisfied by the outcomes of referrals and the manner in which cases were handled. The committee once referred a case of a teacher who raped a girl but they were not told what happened, and in few days, they saw the culprit roaming around on the streets.

The findings from FGDs are inconsistent with the findings in other studies in Philippines, Sri Lanka, Thailand and Vietnam, Nepali and other conflict zones areas in Sub Saharan Africa where communities had strong referral mechanisms in addressing child protection concerns (Wessells, 2016).

It is also evident from literature review that, CBCPMs must link and create coordination and referral mechanisms with other service providers and connect with other formal sectors (UNHCR, 2013) in order to increase access to child protection services. This observation is supported by Davis et al. (2012) in Sub Saharan Africa who also reported that referral was associated with police or local council who are mandated to take action to reduce sexual violence. Plan International (2015) also observes further that, referral is important because it is inappropriate for CBCPMs to investigate criminal offence such as sexual abuse.

\subsection{Speedy Access of Protection Services on Sexual Violence against Children}

The perception that speedy access can address sexual violence concurs with Horn 
et al. (2013) who suggest that the committees in Somali community in refugee's camps had high level of acceptance and were able to respond immediately to any child protection concerns. The only difference was that in Somali community, they were able to mobilize resources within their own community enabling them to fulfil their responsibilities while in Rombo they were waiting for the government and non-government organization to support them. The findings from the study by Save the Children (2011) and Wessells (2016) established that community based groups have been identifying and referring cases of violence and sexual abuse along the systems that link the existing child protection to social protection program and prevent them from further harm by reporting them to the relevant authorities. The current study revealed that speed access to SVAC services motivated parents and the community to use the CBCPMs mechanisms as a conduit for reporting, while other reported directly to the authorities such as Police and Social Welfare department.

\subsection{Mapping of Service Providers in Order to Protect Children against Sexual Violence}

The results of the present study also show that, mapping of service providers can address sexual violence against children. This observation was also reported by UNCHR Geneva (2013) who suggested that it is important to map the existing community structures and mechanisms of working together in combating sexual violence. Consistency to the results, service providers were mapped in order to facilitate in helping children in need of child protection services. The identification points for children in need include schools (by teachers and children themselves), health facilities (by health workers) and community, local council, community based organization community volunteers, child protection committees, para social workers and fit persons (DLC Uganda, 2016). This observation with the observation by CPWG (2012) who also reported that mapping out the resources and services could provide support to children and prevent them from abuse, including sexual abuse. The identified service providers helped referral for children and families in accessing services of addressing their protection needs.

\subsection{Monitoring Children's Rights to Overcome Sexual Violence against Them}

Participants who were involved in FGDs revealed that committee members conducted monitoring of children rights in the community and in schools to assess their situation, especially whether they are safe from sexual violence. The assessment enabled the СBCPMs to identify at risk children and understand better what to do and where to direct their efforts. Similarly, the findings by Plan International (2017) revealed that in Ethiopia committee members were meeting to discuss and monitor their action plans. The situation was quite different in some places in the study area in Rombo District, where very few committees had action plans and consequently they were not monitoring children rights. The study revealed further that, the situation was inconsistent with what is reported in Ethi- 
opia where the established CPCs were assigned a number of households to monitor their own areas. However, monitoring of children was affected by lack of budget to visit different places frequently such as schools and across the communities for monitoring of children.

\subsection{Door to Door Campaigns towards Combating Sexual Violence against Children}

Furthermore, the findings show that door-to-door campaigns did not have any significant effects on protection against sexual violence. This implies that doorto-door campaign was not relevant in the study area. The interview with key informant revealed although the intervention could be useful to reach individual families, the strategy is too demanding in terms of time of moving from one household to another, very costly to visit families because of geographical region, difficulties to access parents during day and difficulties of CBCPMs to have adequate time to go door to door. This finding is not in agreement with the finding in a study by Taruvinga and Molin, (2015) in Zimbabwe and Plan International in Sudanese settlements (2017) who revealed that CPCs were able to travel and use door-to-door approach to deliver messages on child protection. The difference between the findings of the present study in Rombo, Tanzania and those from Zimbabwe and Sudan may be attributed to available resources and short distance between household.

\section{Conclusion and Recommendation}

This study aimed to examine the strategies used by CBCPMs to combat SVAC. The study concluded that awareness raising, provision of advice, communication, child identification have effects on combating SVAC. Furthermore, referral of child abuse cases to authorities, speedy access to protect services, door-to-door campaigns and monitoring of child rights have influence on addressing SVAC. As a result of using these strategies in Rombo district the parents have become vigilant and could identify violations of children rights and respond accordingly, these strategies have also led to increased access to SVAC services and have galvanized community efforts to prevent SVAC. Furthermore, CBCPMs have stimulated collaboration with different stakeholders to provide seamless child protection services on combating SVAC. The study found that the CBCPMs have also improved referrals and reporting of cases to relevant authorities.

Based on the results, the paper recommends that the government and other initiatives should be directed towards the support of CBCPMs in terms of financial resources to strengthen the implementation of the strategies to combat SVAC. CBCPMs need funds if they are to achieve their goals as they will have the ability to reach more community members and educate them on SVAC and their roles in protection of children. It was also concluded that capacity of СВСРMs in terms of skills and knowledge is important. Therefore, the government and other initiatives should be directed on training on SVAC as an important element for $\mathrm{CBCPMs}$ to function well, for example training on child protection. This study 
focused on examining strategies used by $\mathrm{CBCPMs} \mathrm{on} \mathrm{sexual} \mathrm{violence} \mathrm{against} \mathrm{child-}$ ren with views from $\mathrm{CBCPMs} \mathrm{members/implementers,} \mathrm{further} \mathrm{studies} \mathrm{could} \mathrm{be}$ done on the effects of strategies drawing the perception of beneficiaries of the interventions.

\section{Acknowledgements}

We would like to thank Prof. Emmanuel Kigadye and Prof. Magreth Bushesha of the Open University of Tanzania for organizing and facilitating an Intensive Course on Academic Writing and Publishing Skills. We also thank Prof. Heidi Stoeckl and Isabelle Pearson of the London School of Hygiene and Tropical Medicine (LSHTM), Dr. Samuel Likindikoki of Muhimbili University of Health and Allied Sciences (MUHAS) and Dr. Gerry Mshana of National Institute for Medical Research (NIMR) for facilitating the British Academic Writing workshop and review of this manuscript. We are also thankful to Rombo District Council for granting permission for data collection. We also extend our special thanks to all the research assistants, Upendo Ramadhani, Gift Muro and Novatus Njaara.

\section{Conflicts of Interest}

The authors declare no conflicts of interest regarding the publication of this paper.

\section{References}

Abeid, M., Muganyizi, P., Massawe, S., Mpembeni, R., Darj, E., \& Axemo, P. (2015). Knowledge and Attitude towards Rape and Child Sexual Abuse-A Community-Based CrossSectional Study in Rural Tanzania. BMC Public Health, 15, Article No. 428.

https://doi.org/10.1186/s12889-015-1757-7

Bronfenbrenner, U. (1998). Bronfenbrenner's Ecological Model of Child Development, Some Principles of the Ecology of Child Development from the Work Bronfenbrenner. Harvard University Press.

CPWG (Child Protection Working Group) (2012). Working with Community Based Child Protection Committees and Network. Child Protection Working Group.

Davis, R., McCaffery, J., \& Conticini, A. (2012). Strengthening Child Protection Systems in Sub-Saharan Africa: A Working Paper. Inter-Agency Group on Child Protection Systems in sub-Saharan Africa.

Development Links Consult (DLC) (2016). The Handbook for Case Management in Child Protection. Development Links Consult.

Ezekiel, M. J., Kisanga, F., Mosha, I. H., Anaeli, A., Kamazima, S. R., Mpembeni, R., \& Muhondwa, E. P. (2017). Factors Associated with Child Sexual Abuse in Tanzania: A Qualitative Study. Tanzania Journal of Health Research, 19, 1-10. https://doi.org/10.4314/thrb.v19i2.9

Guest, G., Namey, E., \& McKenna, K. (2017). How Many Focus Groups Are Enough? Building an Evidence Base for Nonprobability Sample Sizes. Field Methods, 29, 3-22. https://doi.org/10.1177\%2F1525822X16639015

Gwanyemba, J. K., Kiwia, R. H., \& Zuberi, B. G. (2016). The Effectiveness of Formal and Informal Community-Based Child Protection Mechanisms in Rural Areas of Tanzania: 
Evidences from Selected World Vision Tanzania Projects. Developing Country Studies, 6, 43-47.

Horn, R., Bizimana, D., Nasinyama, S., Aporo, L., Kironde, E., Canavera, M., \& Stark, L. (2013). Community-Based Child Protection Mechanisms among Urban Refugees in Kampala, Uganda: An Ethnographic Study. Child Protection Forum.

ICPREC (International Child Protection Rights and Evaluation Consultants) (2012). Lessons for Protection: A Comparative Analysis of Community Based Child Protection Mechanisms Support by Plan in Asia. International Child Protection Rights and Evaluation Consultants.

LHRC (Legal and Human Rights Centre) (2018). Human Rights Report in Tanzania. Legal and Human Rights Centre.

LHRC (Legal and Human Rights Centre) (2020). Summary of Human Rights Report. Legal and Human Rights Centre.

Ligiero, D., Hart, C., Fulu, E., Thomas, A., \& Radford, L. (2019). What Works to Prevent Sexual Violence against Children: Evidence Review? Together for Girls.

http://togetherforgirls.org/svsolutio

Muzingili, T., \& Mushayamunda, M. (2015). Going beyond Spiritual Synoptic into Child Protection: The Contribution of Church in Caring of Orphans and Vulnerable Children in Rural Zimbabwe. Journal for Studies in Management and Planning, 1, 589-564.

Obi-keguna, C., Agbawodikeizu, U. \& Uche, I. (2017). Communication in Social Work. In U. Okoye, N. Chukwu, \& P. Agwu (Eds.). Social Work in Nigeria: Book of Readings (pp. 60-69). University of Nigeria Press Ltd.

Pereira, C. D. O., Pimentel, R. M. M., Leitão, F. N. C., Moraes, S. D. T. D. A., Maia, P. C. G. G. S., Santos, E. V. D. L. et al. (2020). Sexual Violence against Children and Adolescents Taking Place in Schools: An Integrative Review. Children, 7, Article No. 258. https://doi.org/10.3390/children7120258

Plan International (2015). Strengthening Community Based Mechanisms and State Systems on Child Protection Systems, A POLT Global Initiatives. Plan International.

Plan International (2017). Community-Based Child Protection as a Strategy for Protecting South Sudanese Refugee Children: A Case Study from Gambella, Ethiopia. Plan International.

Radford, L., Allnock, D., \& Hynes, P. (2015). Preventing and Responding to Child Sexual Abuse and Exploitation: Evidence Review. United Nations Children's Fund.

Rosyadi, K. (2016). The Stupid Libido: Searching for the Root Causes of Sexual Violence against Children in Indonesia. Proceedings of the ICECRS, $1,1$. https://doi.org/10.21070/picecrs.v1i1.524

Rwegoshora, H. (2014). A Guide to Social Sciences Research (2nd ed.). Mkuki Na Nyota Publishers, Ltd.

Sarmah, H. K., \& Hazarika, B. B. (2012). Importance of the Size of Sample and Its Determination in the Context of Data Related to the Schools of Greater Guwahati. Bulletin of the Gauhati University Mathematics Association, 12, 55-76.

Save the Children Sweden (2011). A Focus on Child Protection within Social Protection Systems. Tansforming Children Lives. Save the Children Sweden.

Taruvinga, M., \& Molin, M. Q. G. (2015). Child Protection Committees (CPCs) and National Action Plan for Orphans and Vulnerable Children (NAP for OVC) Phase I \& II in Rural Zimbabwe. Journal for Studies in Management and Planning, 1, 572-588.

UNICEF Tanzania, Division of Violence Prevention, National Center for Injury Prevention and Control, Centers for Disease Control and Prevention, and Muhimbili Univer- 
sity of Health and Allied Sciences (2011). Violence against Children in Tanzania: Findings from a National Survey, 2009. Summary Report on the Prevalence of Sexual, Physical and Emotional Violence, Context of Sexual Violence, and Health and Behavioural Consequences of Violence Experienced in Childhood.

UNHCR (Office of the UN High Commissioner for Refugees) (2013). Community Based Child Protection Mechanisms. Office of the UN High Commissioner for Refugees.

URT (United Republic of Tanzania) (2009). The Law of Child Act No. 21 of 2009.

URT (United Republic of Tanzania) (2020). Tanzania in Figures. National Bureau of Statistics, Ministry of Planning.

War Child (2010). Strengthening Community-Based Child Protection Mechanisms in Uganda and the Democratic Republic of Congo. War Child.

Wessells, M. G. (2011). An Ethnographic Study of Community-Based Child Protection Mechanisms and Their Linkage with the National Child Protection System of Sierra Leone. Columbia Group for Children in Adversity.

Wessells, M., Kostelny, K., \& Ondoro, K. (2014). A Grounded View of Commnity-Based Child Protection Mechanism and Their Linkages with the Wider Child Protection System in the Rural and Urban Area in Kenya. Interagency Learning Initiative on Community-Based Child Protection Mechanisms and Child Protection Systems.

Wessells, M. G. (2016). Strengths-Based Community Action as a Source of Resilience for Children Affected by Armed Conflict. Global Mental Health, 3, Article No. e1. https://doi.org/10.1017/gmh.2015.23

Yamane, T. (1967). Statistics: An Introductory Analysis (2nd ed.). Harper and Row. 